\title{
¿NOTICIAS DE ALCANCE? EL CRITERIO PERIODÍSTICO EN LA PUBLICACIÓN DE NOTICIAS EN LAS WEBS MUNICIPALES ESPAÑLAS (2011-2016)
}

\section{Breaking news? Journalistic criteria in the publication of news on Spanish municipal websites (2011-2016)}

Juan-Luis Manfredi-Sánchez, Marta Corcoy-Rius y José-María Herranz-de-la-

Casa

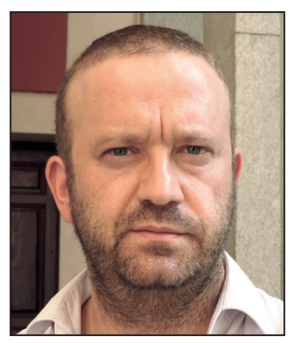

Juan-Luis Manfredi-Sánchez es profesor titular de Periodismo de la Universidad de Castilla-La Mancha. Es el investigador principal del proyecto Comunicación pública, transparencia, rendición de cuentas y participación en los gobiernos locales (CSO2013-46997-R). Ha dirigido Media pluralism monitor in Spain 2015, proyecto del Instituto Europeo de Florencia para medir el pluralismo y la diversidad de los medios y las empresas periodísticas. Es miembro del consejo editorial de Esglobal.com, revista de referencia del periodismo internacional en español. Ha sido finalista del Citi Journalistic Excellence Award 2015 en España.

http://orcid.org/0000-0001-9129-2907

Universidad de Castilla-La Mancha, Facultad de Periodismo Campus universitario, s/n. 16071 Cuenca, España juan.manfredi@uclm.es

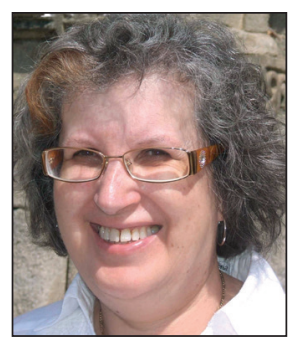

Marta Corcoy-Rius es doctora en Periodismo y Ciencias de la Comunicación por la Universidad Autónoma de Barcelona (UAB). Su experiencia profesional se ha centrado en ejercer como responsable de prensa en ayuntamientos catalanes y en trabajos de investigación y docencia desde la UAB. Está especializada en comunicación local y género. Forma parte del grupo de investigación de la UAB: Laboratorio de Periodismo y Comunicación para la Ciudadanía Plural. Entre sus principales proyectos de investigación destacan el Mapa Infoparticipa, periodismo para la participación ciudadana en el control democrático y Mujeres y hombres en los gobiernos locales catalanes (1979-2015).

http://www.labcompublica.info

http://orcid.org/0000-0001-9283-7884

Universidad Autónoma de Barcelona, Facultad de Ciencias de la Comunicación Edificio I. 08193 Cerdanyola del Vallès, Bellaterra (Barcelona), España marta.corcoy@uab.cat

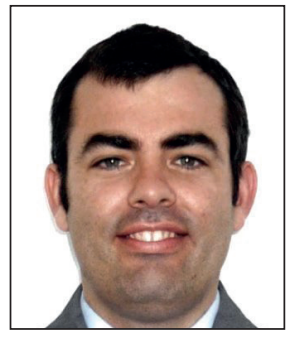

José-María Herranz-de-la-Casa es doctor en Periodismo por la Universidad Complutense de Madrid. Ha trabajado como periodista en el diario deportivo Marca y ha sido profesor de la Universidad Católica de Ávila (UCAV) y de la Universidad Europea Miguel de Cervantes de Valladolid. En ambas universidades ha sido director del Gabinete de Comunicación y Marketing. Es profesor de la Universidad de Castilla-La Mancha.

http://orcid.org/0000-0002-3667-2664

Universidad de Castilla-La Mancha, Facultad de Periodismo Campus universitario, s/n. 16071 Cuenca, España josemaria.herranz@uclm.es

\section{Resumen}

La legislación española recoge la obligación de difundir información entre los administrados, de modo que se mejore la gestión y la administración de las instituciones públicas. Sin embargo, la elaboración y la producción de información no se rigen con criterios periodísticos, sino que se mantiene un cierto control político sobre la naturaleza y el alcance de las noticias. El estudio de las noticias publicadas por seis ayuntamientos en sus webs entre 2011 y 2016 demuestra que la legislación actual ha mejorado el número de items de información pública (no elaborada), pero no su calidad. También destaca la ausencia de innovación en el uso de redes sociales para la promoción de la participación ciudadana en materia informativa. 


\title{
Palabras clave
}

Transparencia; Gobernanza; Ayuntamiento; Periodismo; Participación; Corrupción; Innovación; Sala de prensa.

\begin{abstract}
Spanish legislation includes the obligation to publish information, making it available to citizens, in order to improve public management. However, such information is not created using journalistic criteria, but rather political control. This study of news published by six city councils on their websites between 2011 and 2016 shows that the current legislation has improved the number of public information items (raw data material), but not the quality of the news. It also highlights the lack of innovation in the use of social networks to promote citizen participation with information.
\end{abstract}

\section{Keywords}

Transparency; Governance; City council; Journalism; Participation; Corruption; Innovation; Press rooms.

Manfredi-Sánchez, Juan-Luis; Corcoy-Rius, Marta; Herranz-de-la Casa, José-María (2017). “¿Noticias de alcance? El criterio periodístico en la publicación de noticias en las webs municipales españolas (2011-2016)". El profesional de la información, v. 26, n. 3, pp. 412-420.

https://doi.org/10.3145/epi.2017.may.07

\section{Introducción}

La legislación española recoge las obligaciones de las corporaciones municipales en materia de difusión de la información pública. Existen numerosas fuentes del derecho, si bien dos aparecen como capitales en el desarrollo de la gestión y la administración pública. En primer lugar, la Ley 7/1985, de 2 de abril, de Bases del Régimen Local establece las obligaciones de las corporaciones locales. En el artículo 69 se menciona expresamente la información pública como soporte de la participación ciudadana. En segundo término, el artículo 13 de la Ley 19/2013, de 9 de diciembre, de transparencia, acceso a la información pública y buen gobierno, define la información pública como

"los contenidos o documentos, cualquiera que sea su formato o soporte, que obren en poder de alguno de los sujetos incluidos en el ámbito de aplicación de este titulo y que hayan sido elaborados o adquiridos en el ejercicio de sus funciones".

En este contexto, la bibliografía académica sobre transparencia de las administraciones está bien asentada (GuichotReina, 2014). Encuentra fundamento en la ciencia política, que explica la relación entre buen gobierno y corrupción (Villoria, 2006). Desde el ángulo económico, la gestión pública mejora con la evaluación de los proyectos (Alfaro-Gimeno; Gómez-Miguel, 2016) y el análisis de las demandas de políticas públicas en tiempos de restricciones presupuestarias (Cegarra-Navarro, 2012). En el ámbito periodístico, la demanda de más información pública se relaciona con el saneamiento de fuentes, la vigilancia de los poderes públicos (Diezhandino-Nieto, 2007), el establecimiento de una agenda propia con menos periodismo de declaraciones y, en suma, la recuperación de la función de perro guardián de los valores y los comportamientos de las democracias después de una crisis económica que ha transformado el mercado periodístico (Cabezuelo-Lorenzo, 2013).

El consenso sobre la construcción social de la transparencia ha disparado el número de acciones, informes, instrumentos y métodos para la disposición de la información pública.
Se ha incrementado el rango y la diversidad de los datos disponibles, se han generado documentos de control internos y externos, al tiempo que se han multiplicado las iniciativas ciudadanas de participación a través de presupuestos o acciones de diversa índole. Destacan el Índice de transparencia internacional, el Mapa Infoparticip@, los trabajos de Access-Info o los informes del Greco (Grupo de Estados contra la Corrupción) del Consejo de Europa. Se configura el uso de las tecnologías de la información como un conjunto de herramientas que mejora la gobernanza y estimula la innovación pública (Criado; Rojas-Martín, 2013).

La legislación española recoge las obligaciones de las corporaciones municipales en materia de difusión de la información pública. Existen numerosas fuentes del derecho, si bien dos aparecen como capitales en el desarrollo de la gestión y la administración pública

Sin embargo, mostramos con este trabajo que el crecimiento de la cantidad de información pública disponible no ha aprovechado la transformación digital para incrementar la calidad de dicha información en contenido, método y forma periodística. Se cumple el criterio cuantitativo (hay más información general), pero no rige el principio cualitativo (mejor información, más inteligible). Una sociedad desinformada se expone al descrédito generalizado de la política y del periodismo. La comunicación política debe comprender que el tamaño de las poblaciones no importa, sino la capacidad de ofrecer información concreta de interés público que promueva los objetivos políticos, sociales y culturales comprometidos en el periodismo en las sociedades abiertas.

El presente artículo analiza la evolución de las noticias propias, elaboradas por los gabinetes, y publicadas en las webs municipales durante el período 2011-2016. Los criterios periodísticos de calidad aparecen recogidos en el pro- 
yecto Mapa Infoparticipa. Éste incluye una guía de buenas prácticas profesionales en el ámbito de la comunicación local, un conjunto de items mínimos, así como una estructura y arquitectura acordes para la provisión de información.

\section{Marco teórico}

El buen gobierno supone un salto cualitativo en los modos de administración y gestión pública. La eficiencia de los procesos y la asignación de recursos ha profesionalizado la gestión, de modo que los dirigentes, los funcionarios y el personal público tienen a su disposición un amplio catálogo de instrumentos para la toma de decisiones. En la misma línea, la ciudadanía ha incrementado los niveles de exigencia, en cuanto a su forma o demanda. El gobierno abierto, la transparencia, la participación y la colaboración están en la agenda de la gestión estratégica municipal (Campillo-Alhama, 2013).

En el ámbito periodístico, la demanda de más información pública se relaciona con el saneamiento de fuentes, la vigilancia de los poderes públicos y el establecimiento de una agenda propia con menos periodismo de declaraciones

El buen gobierno incorpora elementos de la comunicación estratégica. La deliberación, el diálogo y la complejidad crean un nuevo marco de comprensión de las políticas públicas (Brugué-Torruella, 2014). A través de la información, el ciudadano conoce cómo actúan los poderes públicos, qué responsabilidades tienen en el ejercicio de su actuación, pregunta libremente sobre aquello que le parece oportuno y se forma su juicio. Las nuevas tecnologías de la sociedad de la información han propiciado el nacimiento de una forma de gobernar más abierta, corresponsable, colaborativa, transparente y receptiva con sus destinatarios, sobre la base de una sociedad más democrática y menos jerárquica. Se origina una distancia del principio de gobierno unilateral para demandar una forma alternativa de gestionar las relaciones y/o responsabilidad y en este sentido la transparencia se vislumbra como un mecanismo ideal para reemplazar el control único y exclusivo de los organismos centralizados, que pasan a ser ineficaces por sí mismos.

Mediante el establecimiento de una relación directa entre periodismo, comunicación pública y democracia, se mejora la cobertura de la gestión pública, la integridad de los representantes y la política en un sentido amplio. Por este motivo, la transparencia a través de la comunicación se ha convertido en uno de los temas recurrentes en la investigación en el área de la comunicación política y la información pública.

La comunicación es estratégica cuando cuenta con recursos (tiempo, personas), afecta a los procesos y promueve unos determinados valores. Así, la estrategia de comunicación se ha diversificado y ocupa una superficie cada vez mayor en las relaciones informativas y comunicativas de las administraciones públicas. Este agregado de comunicación pública "en el contexto municipal se erige como una poderosa herramienta en manos de los equipos de gobierno que permite explicar, justificar $y$, en consecuencia, legitimar las decisiones políticas asumidas en cada período legislativo" (Campillo-Alhama, 2010, p. 47).

Se concreta en acciones de comunicación y

"posee un carácter instrumental y su finalidad particular se traduce en determinados objetivos específicos, establecidos en el ámbito político y/o de gestión administrativa o ejecutiva" (Campillo-Alhama, 2010, p. 49).

La comunicación institucional premia la gestión de los intangibles, dada la naturaleza de los objetivos de las políticas públicas y la prestación de servicios (Canel, 2007). Al tiempo, se ha instalado la promoción de un valor de neutralidad (Luoma-Aho, 2007) que ha importado usos y modelos de gestión privada, tales como la reputación, la credibilidad o la legitimidad.

La comunicación publicitaria se transparenta en cuanto a las inversiones directas, pero se diluye en las otras acciones de relaciones públicas e institucionales como los patrocinios, los mecenazgos o la participación en actividades organizadas por las empresas de comunicación. La comunicación audiovisual, a través de radios y televisiones municipales, no alcanza los estándares de calidad informativa. A menudo se denuncia la falta de pluralismo o la escasez de recursos para la ejecución de proyectos periodísticos relevantes (Media pluralism monitor, 2015).

\section{Una sociedad desinformada se expone al descrédito generalizado de la política y del periodismo}

La función de documentación queda relegada. No actúa como soporte de la memoria institucional ni se asignan recursos para el "subsidio informativo" que da continuidad, bagaje y coherencia institucional (Xifra, 2011). BusteloRuesta (2011, p. 129) considera que la memoria se compone de la revisión diaria de los medios, la gestión del archivo, la producción y difusión de dossiers y

“actualización permanente de documentación básica generada por la institución municipal, así como la observación de estrategias informativas sobre temas específicos llevadas a cabo por otras instituciones, entidades, organizaciones y niveles competenciales administrativos".

En redes sociales se ha traspuesto el modelo unidireccional, se ha promovido la comunicación personal de la alcaldía y no se han explotado las ventajas de la participación digital (García-Orosa; Vázquez-Sande, 2012). Un primer estudio sobre el uso de Twitter en los ayuntamientos confirma la insuficiencia de esta praxis comunicativa en Cataluña (Simelio; Molina-Rodríguez, 2014) y otras carencias similares en Castilla y León (Cabezuelo-Lorenzo et al., 2016). Un estudio preliminar en Portugal indica los mismos resultados (Cardoso-de-Miranda; Muñoz-Cañavate, 2015).

La actividad periodística dentro de los gabinetes de comunicación municipal se ha diluido por tres motivos: En primer lugar, 
porque el enfoque institucional inunda los canales con mensajes de naturaleza propagandística o, cuando menos, parcial.

En segundo lugar, porque la rendición de cuentas en bloque es lo contrario al periodismo. Se desdibuja la transparencia bien sea por falta de elaboración de los contenidos bajo criterios de inteligibilidad o bien porque se facilitan los datos en bruto, sin posibilidad de reelaboración, revisión o difusión.

En tercer lugar, porque no se dan las prácticas profesionales socialmente aceptadas. No se identifican e individualizan las fuentes; desaparece la segunda opinión; se despersonaliza la vida municipal. Las noticias carecen de calidad humana porque se orientan hacia las instituciones y los alcaldes (MorenoSardá et al., 2013), mientras que se desdeñan otras personas o colectivos vinculados al municipio. El colectivo de mujeres aparece infrarrepresentado. Asimismo, no hay contexto para las noticias municipales. No se vincula al plan estratégico o a las políticas públicas emprendidas por la corporación. Sin contexto, el valor del periodismo se reduce.

El gobierno abierto, la transparencia, la participación y la colaboración están en la agenda de la gestión estratégica municipal. El buen gobierno incorpora elementos de la comunicación estratégica

El criterio periodístico se resume en la disposición de información real y tangible sobre el comportamiento del gobierno municipal, el grado de cumplimiento de los presupuestos, la gestión de los recursos colectivos, la dotación de un plan de gobierno, entre otros items. En clave municipal, se resta protagonismo al alcalde y se recupera el papel de la oposición y la sociedad civil. Por último, se observa la necesidad de repensar la narrativa periodística en el sentido de articular los mensajes, dar profundidad y contextos a las noticias y explicar el trasfondo de la actualidad municipal. Aquí la tecnología, la aplicación móvil, la visualización de datos y la adopción de nuevos formatos es fundamental.

\section{Diseño de la investigación}

El trabajo estudia la evolución de las webs municipales en el período 2011-2016, bajo el paraguas de los proyectos de investigación del Mapa Infoparticipa (CSO2013-46997-R y CSO2012-34687). El mapa monitoriza todos los municipios españoles en distintas oleadas. Se utiliza un repertorio de 41 indicadores, posteriormente ampliado a 52 para ajustarlo a la nueva legislación sobre transparencia. La evaluación corre a cargo de un investigador y recibe una segunda comprobación de validez. La guía y la definición del indicador son públicas. Los resultados parciales se publican en tiempo real en la web. Las corporaciones $-y$ cualquier interesado- pueden acceder a su perfil. El objetivo general es la investigación de los recursos, los rasgos y las prácticas de comunicación pública que realizan los ayuntamientos a través de la web. El particular es la identificación en las webs de dichos recursos y de las posibles deficiencias estructurales y de mensaje. Por este motivo se selecciona una muestra que permite el análisis cualitativo: qué variaciones se han observado, qué tipo de tratamiento se ofrece o qué productos periodísticos han aparecido en este período de tiempo.

Los resultados preliminares del proyecto concluyen que la

Tabla 1. Mandato 2011-2015

\begin{tabular}{|l|c|l|l|l|l|}
\hline \multicolumn{1}{|c|}{ Municipio } & \multicolumn{1}{|c|}{$\begin{array}{c}\text { Habitantes } \\
\text { (INE 2014) }\end{array}$} & $\begin{array}{c}\text { Sexo alcalde/ } \\
\text { alcaldesa }\end{array}$ & \multicolumn{1}{|c|}{ Partido político } & \multicolumn{1}{c|}{$\begin{array}{c}\text { Comunidad } \\
\text { autónoma }\end{array}$} \\
\hline Cartagena & 216.451 & Mujer & $P P$ & Murcia \\
\hline Donostia-San Sebastián & 186.126 & Hombre & Bildu & País Vasco & Gipurcia \\
\hline Alzira & 44.518 & Mujer & $P P$ & Comunidad Valenciana & Valencia \\
\hline Manacor & 40.264 & Hombre & Independiente & Baleares \\
\hline
\end{tabular}

Tabla 2. Mandato 2015-2019

\begin{tabular}{|l|l|l|l|l|}
\hline \multicolumn{1}{|c|}{ Municipio } & \multicolumn{1}{|c|}{$\begin{array}{c}\text { Habitantes } \\
\text { (INE 2016) }\end{array}$} & $\begin{array}{c}\text { Sexo alcalde/ } \\
\text { alcaldesa }\end{array}$ & \multicolumn{1}{|c|}{ Partido político } & \multicolumn{1}{c|}{$\begin{array}{c}\text { Comunidad } \\
\text { autónoma }\end{array}$} \\
\hline Cartagena & 217.759 & Hombre & Movimiento Ciudadano & Murcia \\
\hline Donostia-San Sebastián & 186.064 & Hombre & PNV & País Vasco \\
\hline Alzira & 44.488 & Hombre & Compromís & Comunidad Valenciana \\
\hline Manacor & 40.279 & Hombre & VPlencia & Baleares \\
\hline
\end{tabular}

Tabla 3. Alcalde detenido o imputado

\begin{tabular}{|c|c|c|c|c|c|c|}
\hline Municipio & $\begin{array}{l}\text { Habitantes } \\
\text { (INE 2016) }\end{array}$ & $\begin{array}{l}\text { Alcalde procesado y } \\
\text { partido político }\end{array}$ & Año & $\begin{array}{l}\text { Alcalde actual y } \\
\text { partido político }\end{array}$ & $\begin{array}{l}\text { Comunidad } \\
\text { autónoma }\end{array}$ & Provincia \\
\hline Santa Coloma de Gramenet & 117.153 & $\begin{array}{l}\text { Bartomeu Muñoz-Calvet } \\
\text { PSC-PSOE }\end{array}$ & 2009 & $\begin{array}{l}\text { Núria Parlón-Gil } \\
\text { PSC-PSOE }\end{array}$ & Cataluña & Barcelona \\
\hline Colmenar Viejo & 48.020 & $\begin{array}{l}\text { Miguel-Ángel Santamaría-Novoa } \\
P P\end{array}$ & 2016 & $\begin{array}{l}\text { Jorge García-Díaz } \\
\text { PP }\end{array}$ & Madrid & Madrid \\
\hline
\end{tabular}


multiplicación de los items informativos no ha conducido a una mejor información pública de forma automática (Cabezuelo-Lorenzo, Rey-García, Tapia-Frade, 2016). En la práctica se observan las dificultades que tienen los gabinetes de prensa para hacer periodismo bajo criterios de información pública periodística con calidad humana (Moreno-Sardà et al., 2013). En cambio, se observa una evolución positiva: los ayuntamientos aprenden y mejoran la calidad de la información disponible en las webs cuando tienen criterios claros, observables y duraderos. En estos seis años de proyecto, la evolución de algunos de ellos demuestra que se puede mejorar con arreglo a la legislación y con la buena práctica periodística (Manfredi-Sánchez, 2016).

El universo es municipios. La muestra de este artículo se compone de seis ayuntamientos sobre los 399 que tienen más de 20.000 habitantes. Compara la gestión de la información pública de dos equipos de gobierno, el primero entre 2011 y 2015 y el segundo, tras las elecciones municipales de 24 de mayo, entre 2015 y 2016. Los dos últimos casos se emplean para estudiar un asunto concreto, la detención del alcalde o su imputación por corrupción. Se han analizado las noticias publicadas en la web durante el período objeto de investigación hasta que el alcalde renuncia a su cargo, se convoca un pleno extraordinario y se procede a la elección de nuevo alcalde o alcaldesa.

El análisis de contenido se emplea para confirmar la hipótesis inicial con una muestra reducida a través de las siguientes categorías:

- extensión de las noticias y periodicidad;

- ámbitos de referencia (de qué hablan las noticias);

- protagonistas de la información en formato texto y fotográfico (gobierno, oposición, sociedad civil);

- archivo y documentación;

- recursos multimedia; y

- mecanismos de participación ciudadana (incluidas las redes sociales).

Tabla 4. Cartagena

\begin{tabular}{|c|c|c|}
\hline & 2011-2015 & 2015-2019 \\
\hline \multicolumn{3}{|l|}{ 1. Extensión de las noticias } \\
\hline Breves & $19 \%$ & $24 \%$ \\
\hline Noticia tipo (1.000-3.000 caracteres) & $68 \%$ & $58 \%$ \\
\hline Noticia larga ( $>3.000$ caracteres) & $13 \%$ & $18 \%$ \\
\hline \multicolumn{3}{|l|}{ 2. Frecuencia diaria } \\
\hline & 10 noticias & 14 noticias \\
\hline \multicolumn{3}{|c|}{ 3. Ámbitos de referencia: de qué hablan las noticias } \\
\hline & $\begin{array}{l}\text { Predominan las noticias sobre cultura, seguidas de } \\
\text { deportes. Se hace la crónica del Pleno, con informa- } \\
\text { ción de las mociones presentadas por la oposición. }\end{array}$ & $\begin{array}{l}\text { Predominan las noticias sobre cultura, agenda, } \\
\text { seguidas de gestión municipal y deportes. Se hace } \\
\text { la crónica del Pleno con las mociones presentadas } \\
\text { y se informa de acuerdos parciales de la Junta de } \\
\text { Gobierno. }\end{array}$ \\
\hline \multicolumn{3}{|l|}{ 4. Protagonistas de la información } \\
\hline & $\begin{array}{l}\text { Las entidades y actividades ocupan la mayoría } \\
\text { de protagonistas de las noticias, seguidas de la } \\
\text { ciudadanía, equipamientos y personas expertas. La } \\
\text { alcaldesa, los concejales y el Pleno ocupan un espa- } \\
\text { cio menor. Informaciones siempre en positivo. }\end{array}$ & $\begin{array}{l}\text { El alcalde y la vicealcaldesa ganan protagonismo } \\
\text { junto con concejales del equipo de gobierno. Le } \\
\text { siguen las actividades organizadas por entidades y } \\
\text { colectivos. } \\
\text { Los concejales de la oposición ningún protagonis- } \\
\text { mo. } \\
\text { Informaciones siempre en positivo con declaracio- } \\
\text { nes en especial del alcalde. }\end{array}$ \\
\hline \multicolumn{3}{|l|}{ 5. Fotografía } \\
\hline & $\begin{array}{l}\text { Noticias con al menos una foto, sobre todo de ciuda- } \\
\text { danía y carteles. La alcaldesa y concejales aparecen } \\
\text { en un } 25 \% \text { de los casos. En un } 50 \% \text { de los casos } \\
\text { publican galerías de imágenes. } \\
\text { La mayoría no llevan pie de foto identificativo. }\end{array}$ & $\begin{array}{l}\text { La mayoría de las noticias se presentan con una } \\
\text { fotografía. El alcalde tiene un gran protagonismo } \\
\text { seguido de los concejales, deportistas o personas } \\
\text { participantes en actividades de agenda. La ciudada- } \\
\text { nía no aparece. Las fotos de familia sí aparecen. } \\
\text { No van acompañadas de pie de foto. }\end{array}$ \\
\hline \multicolumn{3}{|l|}{ 6. Archivo y documentación } \\
\hline & $\begin{array}{l}\text { La mayoría no ofrecen datos económicos. Sólo en un } \\
5 \% \text { de los casos se dan por ejemplo costes de obras, } \\
\text { inversiones. }\end{array}$ & $\begin{array}{l}\text { No se ofrecen datos económicos ni documentación } \\
\text { asociada. }\end{array}$ \\
\hline \multicolumn{3}{|l|}{ 7. Recursos multimedia } \\
\hline & $\begin{array}{l}\text { Audios y vídeos con declaraciones de cargos electos } \\
\text { o enlaces a otras webs. No hay otros recursos extras. }\end{array}$ & Ninguno \\
\hline \multicolumn{3}{|c|}{ 8. Mecanismos de participación ciudadana (incluidas las redes sociales) } \\
\hline & $\begin{array}{l}\text { No se ofrecen. Opción de compartir con redes } \\
\text { sociales. }\end{array}$ & $\begin{array}{l}\text { No se ofrecen. Opción de compartir con redes } \\
\text { sociales. }\end{array}$ \\
\hline
\end{tabular}




\section{Resultados}

Se exponen los resultados en su valor cuantitativo.

En el caso de los dos ayuntamientos cuyos alcaldes han estado detenidos o bien imputados por corrupción, encontramos un comportamiento similar. Se abandona la noticia y se recurre al comunicado de prensa. En el ayuntamiento de Santa Coloma de Gramenet, el caso Pretoria condujo a la renuncia del alcalde. El primer comunicado, con fecha 2 de noviembre de 2009 , seis días después de la detención explica la causa judicial sin detalles. El 16 de noviembre de 2009 se informa de la convocatoria del pleno para elegir nuevo regidor sin mencionar la causa judicial. Más adelante, en febrero de 2010, se informa de una reorganización interna sin explicar las causas del cese de los concejales implicados en la corrupción. La información desaparece hasta el 30 de enero de 2015, cuando el Ayuntamiento se persona ante la Audiencia Nacional y presenta un escrito de acusación contra el alcalde que había renunciado y por primera vez se menciona el caso Pretoria y se hace referencia a la reunión de una Comisión especial sin que antes de hubiera informado de su constitución.

La función de documentación queda relegada. No actúa como soporte de la memoria institucional ni se asignan recursos para la continuidad y la coherencia institucional

En el caso de Colmenar Viejo, se copia el modelo informativo basado en comunicado oficial escueto, elección rápida de nuevo alcalde sin que se expliquen los motivos y discon-

Tabla 5. San Sebastián

\begin{tabular}{|c|c|c|}
\hline & 2011-2015 & 2015-2019 \\
\hline \multicolumn{3}{|l|}{ 1. Extensión de las noticias } \\
\hline Breves & $63 \%$ & $35 \%$ \\
\hline Noticia tipo (1.000-3.000 caracteres) & $70 \%$ & $24 \%$ \\
\hline Noticia larga (>3.000 caracteres) & $7 \%$ & $41 \%$ \\
\hline \multicolumn{3}{|l|}{ 2. Frecuencia diaria } \\
\hline & 9 noticias & 3 noticias \\
\hline \multicolumn{3}{|c|}{ 3. Ámbitos de referencia: de qué hablan las noticias } \\
\hline & $\begin{array}{l}\text { Predominio claro de las noticias sobre cultura } \\
\text { seguidas de las de gestión municipal y territorio. } \\
\text { La crónica del Pleno no se ofrece, pero sí algunos } \\
\text { acuerdos parciales de la Junta de Gobierno y las } \\
\text { convocatorias. La ciudadanía no es protagonista a } \\
\text { pesar de que se explican informaciones relacionadas } \\
\text { con la participación, de forma unidireccional. }\end{array}$ & $\begin{array}{l}\text { Diversidad de temas con predominio de la gestión } \\
\text { municipal. Le siguen las informaciones de activi- } \\
\text { dades culturales, igualdad, servicios y finalmente } \\
\text { deportes. } \\
\text { La crónica del Pleno no se ofrece, pero sí acuerdos } \\
\text { parciales de la Junta de Gobierno. }\end{array}$ \\
\hline \multicolumn{3}{|l|}{ 4. Protagonistas de la información } \\
\hline & $\begin{array}{l}\text { Predominio de las entidades y las actividades de } \\
\text { agenda y servicios. } \\
\text { Poco protagonismo de la ciudadanía. } \\
\text { El alcalde y los concejales del equipo de gobierno no } \\
\text { llegan al } 10 \% \text {. } \\
\text { La oposición ningún protagonismo. }\end{array}$ & $\begin{array}{l}\text { Destacable protagonismo del alcalde y algunos } \\
\text { concejales en las noticias sobre explicación de la } \\
\text { gestión. El resto son informaciones de actividades } \\
\text { de agenda y servicios. } \\
\text { La ciudadanía no está presente. } \\
\text { La oposición ningún protagonismo. Noticias en } \\
\text { positivo acompañadas de declaraciones de cargos } \\
\text { electos. }\end{array}$ \\
\hline \multicolumn{3}{|l|}{ 5. Fotografía } \\
\hline & $\begin{array}{l}\text { Las fotografías corresponden a edificios, paisaje, } \\
\text { obras y fotos de recurso. El alcalde y los concejales } \\
\text { no superan el } 15 \% \text {. La mayoría no lleva pie de foto. }\end{array}$ & $\begin{array}{l}\text { Predominan las fotos del alcalde, solo o acompaña- } \\
\text { do de concejales. } \\
\text { Le siguen las fotos de recurso, imágenes y carteles } \\
\text { de actividades. } \\
\text { Las fotos no llevan pie. }\end{array}$ \\
\hline \multicolumn{3}{|l|}{ 6. Archivo y documentación } \\
\hline & $\begin{array}{l}\text { Datos económicos y documentación asociada en el } \\
6 \%\end{array}$ & No se aprecian. \\
\hline \multicolumn{3}{|l|}{ 7. Recursos multimedia } \\
\hline & $\begin{array}{l}\text { Todas las noticias llevan enlaces a otras webs, artícu- } \\
\text { los relacionados con la temática y/o documentos. }\end{array}$ & $\begin{array}{l}\text { La mayoría no lleva enlaces a otras webs o artículos } \\
\text { salvo algunas excepciones. }\end{array}$ \\
\hline \multicolumn{3}{|c|}{ 8. Mecanismos de participación ciudadana (incluidas las redes sociales) } \\
\hline & $\begin{array}{l}\text { Se ofrece la posibilidad de participar a través de un } \\
\text { enlace: ¡Participa! Suscripción a las noticias vía redes } \\
\text { sociales. }\end{array}$ & $\begin{array}{l}\text { No se ofrecen mecanismos de participación. Sola- } \\
\text { mente se da la opción de compartir con las redes } \\
\text { sociales. }\end{array}$ \\
\hline
\end{tabular}


tinuidad de la información. Así, se informa que el 10 de noviembre de 2016 Miguel-Ángel Santamaría-Novoa presenta su dimisión, pero no se informa de los cargos judiciales.

La muestra ofrece espacio para la discusión. La web es una oportunidad para la mejora de la información pública, pero se demuestra una cierta deficiencia en dicho proceso. La evolución 2011-2016 no ofrece evidencias de un cambio sustancial en las rutinas de producción informativa, de modo que las tecnologías no han redundado en una mejor calidad informativa. La transparencia no es una cuestión legal, sino cultural. Los representantes políticos, los técnicos municipales y los periodistas tiene que renovar los procesos de información, aprovechar las oportunidades de la web y ampliar las posibilidades de la participación a través de redes sociales.

\section{Conclusiones}

La primera conclusión es la capacidad de transformación de la información pública con criterios periodísticos, cuando rige el criterio profesional y la actividad dirigida por profesionales. La evaluación durante estos dos mandatos permite observar la evolución de la información publicada, de los ritmos de producción, de las normas editoriales y de otros criterios de calidad humana, según la bibliografía. Se puede cambiar y mejorar la gestión de la información pública. La muestra indica que no se aplican usos periodísticos.

La segunda conclusión consiste en la falta de interés en que esta transformación se produzca. Ni el nuevo marco legal ni el cambio de titular en la alcaldía es suficiente. La comparativa de los dos períodos de gestión ofrece pocas mejoras sustanciales en la elaboración de las informaciones según el color político o el inicio de una nueva legislatura. En la muestra, se mantienen en general las mismas pautas de dar prioridad a las informaciones de agenda, organizadas por las propias entidades. No queda claro este concepto de "auto" fuente, de modo de que se confunde o no se explicita con

Tabla 6. Alzira

\begin{tabular}{|c|c|c|}
\hline & 2011-2015 & 2015-2019 \\
\hline \multicolumn{3}{|l|}{ 1. Extensión de las noticias } \\
\hline Breves & $6 \%$ & $65 \%$ \\
\hline Noticia tipo (1.000-3.000 caracteres) & $79 \%$ & $35 \%$ \\
\hline Noticia larga ( $>3.000$ caracteres) & $15 \%$ & $0 \%$ \\
\hline \multicolumn{3}{|l|}{ 2. Frecuencia } \\
\hline & 3,3 diarias & 2,7 diarias \\
\hline \multicolumn{3}{|c|}{ 3. Ámbitos de referencia: de qué hablan las noticias } \\
\hline & $\begin{array}{l}\text { Predominan las noticias sobre ocupación y cultura. } \\
\text { Siguen las de territorio. No se dan informaciones } \\
\text { sobre el Pleno ni acuerdos de la Junta de Gobierno. }\end{array}$ & $\begin{array}{l}\text { Gestión municipal, obras, medio ambiente, promo- } \\
\text { ción económica y ocupación son los temas predo- } \\
\text { minantes. Ninguna información sobre deportes ni } \\
\text { actividades de entidades. } \\
\text { La crónica del Pleno no se publica, tampoco los } \\
\text { acuerdos de la Junta de Gobierno. }\end{array}$ \\
\hline \multicolumn{3}{|l|}{ 4. Protagonistas de la información } \\
\hline & $\begin{array}{l}\text { Predominio de protagonistas institucionales, ayun- } \\
\text { tamiento y alcalde. Los concejales, prácticamente } \\
\text { invisibles. También se muestran equipamientos y } \\
\text { servicios. La ciudadanía ocupa un protagonismo } \\
\text { residual. La oposición ningún protagonismo. }\end{array}$ & $\begin{array}{l}\text { Predominan los concejales explicando acuerdos o } \\
\text { gestión. Ningún protagonismo del alcalde ni tam- } \\
\text { poco de la ciudadanía ni las entidades. } \\
\text { La oposición no aparece. } \\
\text { Noticias en positivo. }\end{array}$ \\
\hline \multicolumn{3}{|l|}{ 5. Fotografía } \\
\hline & $\begin{array}{l}\text { La mayoría de las noticias no llevan foto. } \\
\text { Cuando sí, es la alcaldesa, seguida de edificios y } \\
\text { obras. La ciudadanía tiene un protagonismo inferior } \\
\text { al } 6 \% \text {. } \\
\text { Las fotos no llevan pie. }\end{array}$ & $\begin{array}{l}\text { La mayoría de las noticias van acompañadas de } \\
\text { al menos una foto. Éstas consisten en reuniones } \\
\text { de trabajo de concejales o en actos protocolarios. } \\
\text { También fotos de recurso, de obras o edificios y } \\
\text { servicios. } \\
\text { El alcalde ningún protagonismo. }\end{array}$ \\
\hline \multicolumn{3}{|l|}{ 6. Archivo y documentación } \\
\hline & $\begin{array}{l}\text { La mayoría no ofrecen datos económicos ni docu- } \\
\text { mentación asociada salvo alguna excepción en que } \\
\text { se da el coste de una obra o una inversión. }\end{array}$ & No se ofrecen datos económicos. \\
\hline \multicolumn{3}{|l|}{ 7. Recursos multimedia } \\
\hline & $\begin{array}{l}\text { Ninguna noticia lleva incorporado enlace a web, } \\
\text { vídeos ni ningún documento asociado. }\end{array}$ & Ningún recurso multimedia. \\
\hline \multicolumn{3}{|c|}{ 8. Mecanismos de participación ciudadana (incluidas las redes sociales) } \\
\hline & $\begin{array}{l}\text { No se ofrecen mecanismos de participación ciudada- } \\
\text { na. Se da la opción de compartir con redes sociales. }\end{array}$ & $\begin{array}{l}\text { No se ofrecen mecanismos de participación ciu- } \\
\text { dadana. Sólo se da la opción de compartir con las } \\
\text { redes sociales. }\end{array}$ \\
\hline
\end{tabular}


claridad quién tiene la autoría de la organización. A menudo la oposición no tiene protagonismo ni ejerce el rol de control de la gestión del equipo de gobierno. La crónica del Pleno no se publica en la mayoría de ayuntamientos, por lo que este género queda disminuido. Los mecanismos de participación totalmente insuficientes o nulos. Destaca el protagonismo que adquiere el alcalde en ayuntamientos que han registrado un color político de signo muy distinto a su antecesor como es el caso de Cartagena o San Sebastián. Tampoco se detectan diferencias si quien gobierna es un hombre o una mujer.

En la muestra hemos seleccionado dos casos de corrupción, por su carácter particular. Sin duda, es noticioso y de interés para los ciudadanos. Sin embargo, cuando se produce el cambio en la alcaldía, se observa una mecánica no profesional. Se parte de un comunicado oficial firmado por el equipo de gobierno en que no se explican los motivos que han provocado la renuncia del alcalde ni la urgencia de la misma. A posteriori, se borra el rastro de las noticias relacionadas con el suceso delictivo. El ayuntamiento no actúa de centro de documentación ni de información. El uso patrimonial del canal informativo es un ejemplo de la falta de cultura de transparencia y el mal uso de la información municipal.

La actividad periodística dentro de los gabinetes de comunicación municipal se ha diluido por tres motivos: el enfoque institucional-político, la rendición de cuentas en bloque y no desagregada, y la mala práctica profesional

Por último, se observa una cuarta conclusión que es la ausencia de innovación en los formatos y los estilos periodísticos para información municipal. No se emplean elementos rudimentarios de documentación o multimedia, por lo que otras iniciativas más avanzadas ni se plantean. En cuanto a la participación, las redes sociales no han incrementado los mecanismos de participación.

Tabla 7. Manacor

\begin{tabular}{|c|c|c|}
\hline & 2011-2015 & 2015-2019 \\
\hline \multicolumn{3}{|l|}{ 1. Extensión de las noticias } \\
\hline Breves & $33 \%$ & $0 \%$ \\
\hline Noticia tipo (1.000-3.000 caracteres) & $67 \%$ & $100 \%$ \\
\hline Noticia larga (>3.000 caracteres) & $0 \%$ & $0 \%$ \\
\hline \multicolumn{3}{|l|}{ 2. Frecuencia } \\
\hline & Un día a la semana & Un día a la semana \\
\hline \multicolumn{3}{|c|}{ 3. Ámbitos de referencia: de qué hablan las noticias } \\
\hline & $\begin{array}{l}\text { Predominan las noticias sobre gestión general, se- } \\
\text { guidas de las de territorio, Pleno y Junta de gobierno } \\
\text { y deportes. La crónica del Pleno no se hace. }\end{array}$ & $\begin{array}{l}\text { Predominan las noticias sobre cultura, educación y } \\
\text { deportes. No se hace la crónica del Pleno. }\end{array}$ \\
\hline \multicolumn{3}{|l|}{ 4. Protagonistas de la información } \\
\hline & $\begin{array}{l}\text { Predominio de protagonistas institucionales, } \\
\text { ayuntamiento y alcalde. Las entidades ocupan un } \\
\text { porcentaje menor y la ciudadanía no aparece, así } \\
\text { como tampoco los concejales ni miembros de la } \\
\text { oposición. Informaciones siempre en positivo, sin } \\
\text { contrastar con la oposición. Contenido relacionado } \\
\text { con servicios públicos y trámites. }\end{array}$ & $\begin{array}{l}\text { Predominio de protagonistas institucionales, alcalde } \\
\text { y concejales del equipo de gobierno. Las noticias } \\
\text { llevan declaraciones de los cargos electos y también } \\
\text { de representantes de entidades, según el contenido. } \\
\text { Siguen sin contrastar con la oposición. Y la ciudada- } \\
\text { nía no tiene protagonismo. } \\
\text { Contenido relacionado con gestión municipal con } \\
\text { fuerte presencia del alcalde. }\end{array}$ \\
\hline \multicolumn{3}{|l|}{ 5. Fotografía } \\
\hline & $\begin{array}{l}\text { La mayoría de las noticias no llevan foto. Las que } \\
\text { sí llevan, muestran protagonistas institucionales, } \\
\text { alcalde, concejales y una galería de imágenes. } \\
\text { No llevan pie de foto. }\end{array}$ & $\begin{array}{l}\text { Todas las noticias van acompañadas de una o dos } \\
\text { fotografías en las que predominan los protagonis- } \\
\text { tas institucionales, alcalde, concejales o miembros } \\
\text { de entidades, según contenido. También fotos de } \\
\text { familia. } \\
\text { No llevan pie de foto. }\end{array}$ \\
\hline \multicolumn{3}{|l|}{ 6. Archivo y documentación } \\
\hline & $\begin{array}{l}\text { No se ofrecen datos económicos ni documentación } \\
\text { asociada }\end{array}$ & $\begin{array}{l}\text { No se ofrecen datos económicos ni documentación } \\
\text { asociada excepto en un caso. }\end{array}$ \\
\hline \multicolumn{3}{|l|}{ 7. Recursos multimedia } \\
\hline & No & No \\
\hline \multicolumn{3}{|c|}{ 8. Mecanismos de participación ciudadana (incluidas las redes sociales) } \\
\hline & No se oferta & $\begin{array}{l}\text { Se ha incorporado la opción de compartir con redes } \\
\text { sociales, correo }\end{array}$ \\
\hline
\end{tabular}




\section{Notas}

Este artículo es producto del proyecto de investigación “Comunicación pública, transparencia, rendición de cuentas y participación en los gobiernos locales (Glocalcom)", con referencia CSO2013-46997-R, financiado por el Ministerio de Economía y Competitividad, dentro del Plan Nacional de I+D+i del Programa estatal de investigación, desarrollo e innovación orientada a los Retos de la Sociedad.

\section{Bibliografía}

Alfaro-Gimeno, César; Gómez-Miguel, Javier (2016). “Un sistema de indicadores para la medición, evaluación, innovación y participación orientado a la Administración Pública". Methaodos. Revista de ciencias sociales, v. 4, n. 2, pp. 274-290.

https://doi.org/10.17502/m.rcs.v4i2.124

Brugué-Torruella, Quim (2014). "Políticas públicas: entre la deliberación y el ejercicio de autoridad". Cuadernos de gobierno y administración pública, v. 1, n. 1, pp. 37-55.

https://doi.org/10.5209/rev_CGAP.2014.v1.n1.45157

Bustelo-Ruesta, Carlota (2011). "Los grandes temas relacionados con la gestión de documentos: desafíos y oportunidades". El profesional de la información, v. 20, n. 2, pp. 129-134.

https://doi.org/10.3145/epi.2011.mar.01

Cabezuelo-Lorenzo, Francisco (2013). "Cinco años de crisis en el mercado de la comunicación (2008-2013)". Historia y comunicación social, v. 18, pp. 703-715. https://doi.org/10.5209/rev_HICS.2013.v18.44358

Cabezuelo-Lorenzo, Francisco; Rey-García, Pablo; TapiaFrade, Alejandro (2016). "Análisis de las herramientas de control ciudadano sobre los representantes públicos: la transparencia informativa municipal en Castilla y León". Revista latina de comunicación social, v. 71, pp. 1.261-1.279 https://doi.org/10.4185/RLCS-2016-1145

Campillo-Alhama, Concepción (2010). “Comunicación pública y administración municipal: una propuesta de modelo estructural". Pensar la publicidad: revista internacional de investigaciones publicitarias, v. 4, n. 1, pp. 45-62.

http://revistas.ucm.es/index.php/PEPU/article/view/ PEPU1010120045A

Campillo-Alhama, Concepción (2013). “Gestión de la información y su evaluación en los gabinetes de comunicación municipal". El profesional de la información, v. 22, n. 6, pp. 515-521.

http://dx.doi.org/10.3145/epi.2013.nov.03

Canel, María-José (2007). La comunicación de las instituciones públicas. Madrid: Tecnos. ISBN: 9788430946556

Cardoso-de-Miranda, Eduardo-Alfredo; Muñoz-Cañavate, Antonio (2015). "Los sitios web como servicios de información al ciudadano: un estudio sobre los 308 ayuntamientos de Portugal". Anales de documentación, v. 18, n. 1. http://dx.doi.org/10.6018/analesdoc.18.1.212681

Cegarra-Navarro, Juan-Gabriel; Córdoba-Pachón, José-Ro- drigo; Moreno-Cegarra, José-Luis (2012). "E-government and citizens' engagement with local affairs through e-websites: The case of Spanish municipalities". International journal of information management, v. 32, n. 5, pp. 469-478. https://doi.org/10.1016/j.ijinfomgt.2012.02.008

Centre for Media Pluralism and Media Freedom (2015). Media Pluralism Monitor Spain 2015.

http://monitor.cmpf.eui.eu

Criado, J. Ignacio; Rojas-Martín, Francisco (eds.) (2013). Las redes sociales digitales en la gestión y las políticas públicas. Avances y desafíos para un gobierno abierto. Barcelona: EAPC. ISBN: 9788469593974

http://americo.usal.es/iberoame/sites/default/files/criado_ redes_sociales_digitales.pdf

Diezhandino-Nieto, María-Pilar (2007). Periodismo y poder: políticos, periodistas y ciudadanos voluntariamente desinformados. Madrid: Pearson Prentice Hall. ISBN: 978 8483223666

García-Orosa, Berta; Vázquez-Sande, Pablo (2012). “Los gabinetes de prensa institucionales en los ayuntamientos españoles en internet". Estudios sobre el mensaje periodístico, v. 18 , pp. $405-412$.

https://doi.org/10.5209/rev_ESMP.2012.v18.40995

Guichot-Reina, Emilio (2014). Transparencia y buen gobierno. Madrid: Aranzadi. ISBN: 9788490591802

Luoma-Aho, Vilma (2007). "Neutral reputation and public sector organizations". Corporate reputation review, v. 10, n. 2, pp. 124-144.

https://doi.org/10.1057/palgrave.crr.1550043

Manfredi-Sánchez, Juan-Luis (2016). “A major disappointment: The quest for transparency among Spanish municipalities". International journal of media and cultural politics, v. 12 , n. 2, pp. 265-269.

https://goo.gl/GTYO2T

https://doi.org/10.1386/macp.12.2.265_7

Moreno-Sardà, Amparo; Rodríguez-Navas, Pedro-Molina; Corcoy-Rius, Marta; Aguilar-Pérez, Antonio; Borràs-Farran, Miquel (2013). "Infoparticip@: periodismo para la participación ciudadana en el control democrático. Criterios, metodologías y herramientas". Estudios sobre el mensaje periodístico, v. 19, n. 2, pp. 783-803.

http://dx.doi.org/10.5209/rev_ESMP.2013.v19.n2.43471

Simelio-Solà, Núria; Rodríguez-Navas, Pedro-Molina (2014). “Comunicación pública y participación ciudadana. EI uso de Twitter en los ayuntamientos de Cataluña". Historia y comunicación social, v. 19, pp. 479-490.

http://dx.doi.org/10.5209/rev_HICS.2014.v19.45043

Villoria-Mendieta, Manuel (2006). La corrupción política. Madrid: Síntesis. ISBN: 9788497563573

Xifra, Jordi (2011). "Subsidios informativos y función documental de las salas de prensa online de los ministerios españoles". El profesional de la información, v. 20, n. 3, pp. 270-275.

https://doi.org/10.3145/epi.2011.may.04 